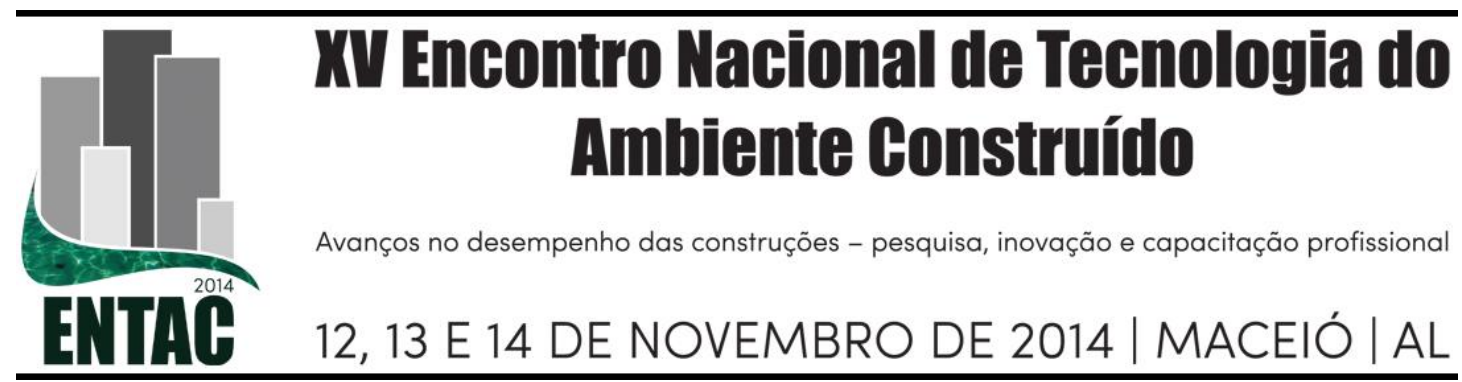

\title{
DESEMPENHO TÉRMICO DE HABITAÇÃO MULTIFAMILIAR DO PROGRAMA MINHA CASA MINHA VIDA EM MACEIÓ - AL
}

\author{
BATISTA, Juliana Oliveira (1); PEIXOTO, Ithiane Maria Leite (2); \\ CAVALCANTE, Kherolyn Ellen Lopes (3); LIMA, Izabella Medeiros de (4) \\ (1) FAU/UFAL, e-mail: juliana.batista@ fau.ufal.br, (2) FAU/UFAL, e-mail:
} ithianemaria_leitepeixoto@yahoo.com.br, (3)FAU/UFAL, e-mail: kherolyncavalcante@gmail.com, (4) FAU/UFAL, e-mail: bellamedeiros@hotmail.com

\begin{abstract}
RESUMO
O Programa Minha Casa Minha Vida (PMCMV) engloba hoje quase a totalidade da habitação produzida para as classes média e média baixa no Brasil. Entretanto, a qualidade arquitetônica dos empreendimentos não é condizente com as dimensões do Programa, inclusive sob o ponto de vista da adequação climática. Buscando a melhoria da qualidade desses empreendimentos, a norma NBR 15575-1 (ABNT, 2013) define parâmetros mínimos de desempenho para habitações, enquanto o Regulamento Técnico da Qualidade de Edificações Residenciais - RTQ-R (BRASIL, 2013) reúne uma série de parâmetros destinados à avaliação da eficiência energética, incluindo-se o desempenho térmico da envoltória. Ambas referências utilizam o procedimento de simulação computacional, embora por meio de abordagens diferenciadas. Este artigo apresenta resultados parciais de uma pesquisa de iniciação científica e tem como objetivo avaliar o desempenho térmico de um edifício multifamiliar representativo do PMCMV na cidade de Maceió - AL, confrontando as abordagens de avaliação propostas pela NBR 15575-1 e pelo RTQ-R. Para tal foram realizadas simulações com o software EnergyPlus v. 8.1 de um edifício com planta "H", 4 pavimentos e 4 unidades habitacionais por andar. O software PHOENICS VR 3.6.1 (CHAM, 2005) foi utilizado para análise qualitativa da ventilação natural. Os resultados demonstraram que unidades classificadas com níveis "intermediário" ou "superior" pela NBR 15575-1 obtiveram nível "E” de eficiência energética, a mais baixa classificação possível, ultrapassando o limite do indicador graus-hora de resfriamento estabelecido pelo RTQ-R. Pode-se concluir que o procedimento de simulação adotado pela NBR 15575-1 apresenta limitações importantes, por ser restrito ao dia típico e empregar uma taxa de ventilação fixa, especialmente nas localidades onde a ventilação natural é a principal estratégia bioclimática recomendada. Já o RTQ-R avalia a influência da variação anual da temperatura no desempenho térmico, porém apresenta limitações quanto ao efeito da ventilação natural no interior dos ambientes.
\end{abstract}

Palavras-chave: Habitações multifamiliares, desempenho térmico, simulação computacional.

\begin{abstract}
The Minha Casa Minha Vida Program (PMCMV) congregates today almost the totality of housing production for lower middle and middle classes in Brazil . However, the architectural quality of projects are not consistent with PMCMV relevancy, highlighting the climate adaptation aspect. Searching for better quality of housing production, the standard NBR 15575-1 (ABNT, 2013) defines minimum performance parameters for these buildings, while the Technical Regulation on Quality of Residential Buildings - RTQ-R (BRAZIL, 2013) lists a set of evaluation parameters for energy efficiency, including thermal performance of buildings envelope. Both references use computer simulation for assessing the thermal and /or energy performance, but using different approaches. This work presents the partial results of an undergraduate survey that aims to evaluate the thermal performance of a representative multifamily building of PMCMV in Maceió - AL, comparing the approaches for assessing thermal performance proposed by NBR 15575-1 and by RTQ-R. The method is based in computer simulations performed with EnergyPlus software v. 8.1. of a four storied building, "H" plan floor shape and 4 units per floor. For assessing the natural ventilation performance, it was used PHOENICS VR 3.6. software (CHAM, 2005).
\end{abstract}


The results demonstrated that rooms classified as "intermediate " or "higher " levels by NBR 15575-1 obtained "E" levels of energy efficiency, the lower possible, because the internal environment exceeded the limit of cooling degree hours set by RTQ-R. It can be concluded that the NBR 15575-1 simulation procedure presents important limitations, since its procedure is restricted to the summer typical day, besides adopts fixing ventilation rates, especially where natural ventilation is the main cooling strategy recommended. On the other hand, RTQ $-\mathrm{R}$ assesses the influence of annual variation of temperature in thermal performance, but it is limited for assessing the effect of natural ventilation inside and outside the buildings.

Keywords: Multifamily housing, thermal performance, computer simulation.

\section{INTRODUÇÃ̃o}

O Programa Minha Casa Minha Vida (PMCMV), criado em março de 2009, engloba hoje a maior parte da habitação produzida para as classes média e média baixa no Brasil. Lançado pelo governo federal em março de 2009 tinha como meta inicial construir dois milhões de habitações até 2014, priorizando famílias com renda bruta de até $\mathrm{R} \$ 1.600,00$, setor que concentra o maior déficit habitacional do país, abrangendo também famílias com renda de até $\mathrm{R} \$ 5.000,00$ (entre 3 e 10 salários mínimos) (CARTILHA PMCMV, 2013).

Com as transformações econômicas ocorridas na última década, destacando-se a ampliação da oferta de empregos formais e o aumento do salário mínimo, ampliou-se a capacidade de endividamento de parte da população, inclusive as classes média e média baixa. Neste contexto, o PMCMV é responsável pelo aquecimento do mercado imobiliário. Entretanto, a questão que se coloca é qual o nível de qualidade desses novos empreendimentos, pois acima de metas quantitativas, deveria ser priorizada a qualidade arquitetônica e urbanística da moradia.

Em Maceió, caracterizada pelo clima quente e úmido, a ventilação natural e o sombreamento das aberturas destacam-se como estratégias capazes de aprimorar o desempenho térmico das edificações. Recentemente, o surgimento da norma NBR 15575-1 (ABNT, 2013) definiu parâmetros mínimos de desempenho para habitações, enquanto o Regulamento Técnico da Qualidade de Edificações Residenciais - RTQ-R (BRASIL, 2013) reuniu uma série de parâmetros destinados à avaliação da eficiência energética, incluindo o desempenho térmico da envoltória destas edificações. Ambas as referências utilizam o procedimento de simulação computacional para avaliar o desempenho térmico e/ou energético, embora por meio de abordagens diferenciadas.

O procedimento de simulação adotado NBR 15575-1 utiliza como referência para a avaliação do desempenho térmico da edificação um dia típico de projeto. Para cidades situadas na zona bioclimática 8, a exemplo de Maceió, a norma recomenda que a avaliação seja realizada apenas para o verão. O desempenho mínimo é alcançado quando a temperatura máxima no interior do ambiente é inferior à temperatura máxima externa no dia típico de verão, que no caso de Maceió corresponde a $32,2^{\circ} \mathrm{C}$ (ABNT, 2013). Portanto, não se avalia a influência da variação anual da temperatura no desempenho térmico da edificação. Além disso, não são consideradas a ocupação e as cargas térmicas internas, empregando-se uma taxa de ventilação fixa para a simulação.

Já o RTQ-R (BRASIL, 2013), destinado à etiquetagem de eficiência energética de habitações unifamiliares e multifamiliares, utiliza a simulação computacional para avaliar o desempenho termo-energético do modelo virtual representativo da edificação real, comparando-a com diferentes modelos de referência, simulados de acordo com características construtivas que incorporam estratégias projetuais destinadas a assegurar 
níveis de desempenho, que variam de "A" (maior nível) a "E" (menor nível). O desempenho térmico da envoltória é requisito avaliado individualmente, que junto com a avaliação do sistema de aquecimento de água compõe a classificação final do nível de eficiência energética da edificação. Quanto à avaliação da envoltória, este método considera a variação das condições climáticas e também as condições de uso e ocupação dos ambientes internos ao longo do ano. Como parâmetro para a classificação do desempenho, utiliza-se o indicador graus hora de resfriamento, o qual representa o somatório da diferença entre a temperatura operativa horária e a temperatura de base, quando a primeira está acima da temperatura de base (BRASIL, 2013). Ou seja, o parâmetro de desempenho considera o caráter dinâmico do comportamento térmico do edifício, ao invés de restringir a avaliação apenas ao dia típico de verão.

Convém salientar que os procedimentos de simulação computacional descritos pela NBR 15575-1 e pelo RTQ-R utilizam métodos distintos de avaliação. Baseiam-se, respectivamente, na temperatura máxima do ar de um dia típico e no total anual de graus hora de resfriamento, este calculado em função da temperatura operativa. Quanto à questão do conforto térmico, enquanto a NBR 15575-1 admite como nível mínimo a manutenção da temperatura do ar máxima no interior da edificação abaixo de $32,2^{\circ} \mathrm{C}$ para Maceió, o RTQ-R contabiliza os graus hora de resfriamento a partir da temperatura operativa de $26^{\circ} \mathrm{C}$. Portanto, cada referência estabelece uma classificação diferenciada, mas ambas qualificam o comportamento da edificação frente a parâmetros térmicos préestabelecidos. Considerando-se as distinções entre os métodos de avaliação ora apresentados, é possível questionar qual seria a classificação do desempenho térmico de uma mesma edificação quando submetida à análise segundo a NBR 15575-1 e o RTQ$\mathrm{R}$, utilizando-se a mesma ferramenta de simulação e o mesmo arquivo climático. Tal questionamento fundamenta o objetivo do presente artigo, conforme é apresentado a seguir.

\section{OBJETIVO}

O presente trabalho tem como objetivo avaliar o desempenho térmico de um edifício multifamiliar representativo do PMCMV na cidade de Maceió - AL, confrontando as abordagens de avaliação de desempenho térmico propostas pela NBR 15575-1 e pelo RTQ-R, aprofundando-se a análise do efeito da ventilação natural nos ambientes em estudo.

\section{MÉTODO}

O método adotado no presente trabalho utiliza o procedimento de simulação computacional para avaliar o desempenho térmico de unidades habitacionais de um edifício multifamiliar, localizadas no pavimento térreo e na cobertura. Para tal, foi utilizado o software EnergyPlus v. 8.1 (US-DOE, 2014) e as simulações foram realizadas de acordo com as prescrições da NBR 15575-1 (ABNT, 2013) e do RTQ-R (BRASIL, 2013). Também foram realizadas simulações com o software PHOENICS VR 3.6.1 (CHAM, 2005), para avaliar a incidência da ventilação no exterior do edifício.

\subsection{Caracterização do edifício}

O modelo de edifício a ser simulado caracteriza-se pela planta com formato "H", tipologia recorrente nos empreendimentos do PMCMV em Maceió. O edifício possui 4 
pavimentos e 4 unidades habitacionais (UHs) por andar, sendo a circulação vertical realizada por meio de escadas (Figuras 1 e 2).
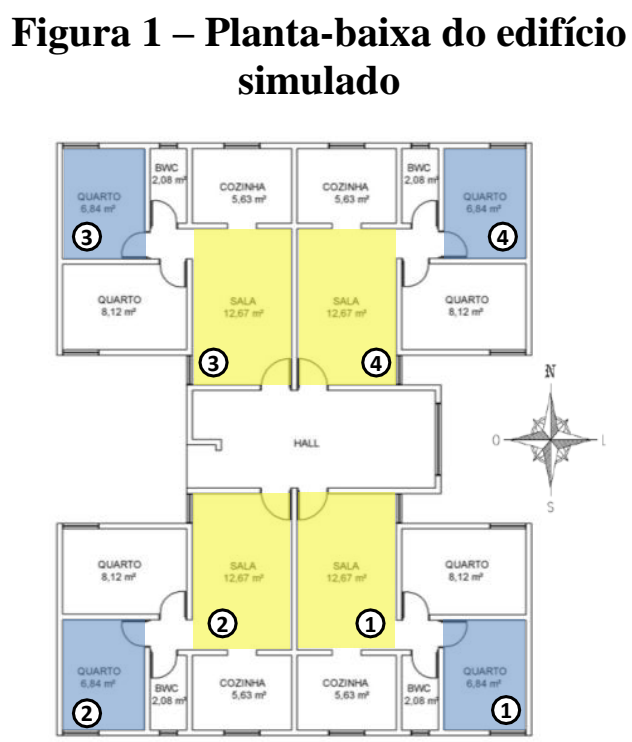

\section{Figura 2 - Modelo computacional do edifício}

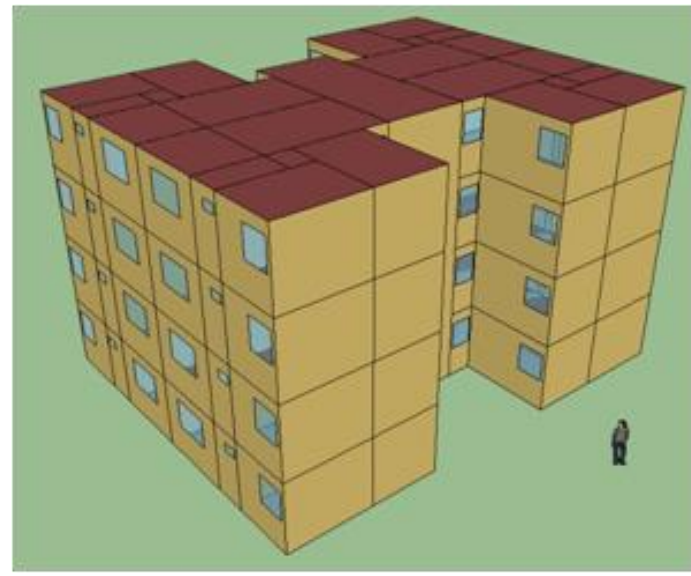

Com relação às aberturas, foram adotadas esquadrias de correr ( 2 folhas), com vidros simples $3 \mathrm{~mm}$. Não foram utilizados dispositivos de proteção solar, conforme se verifica em vários empreendimentos habitacionais de padrão semelhante em Maceió.

A envoltória dos modelos é composta por paredes em blocos cerâmicos com seis furos, com reboco em ambas as faces, pintada na cor branca (absortância $=0,2$ ), com espessura total de $14 \mathrm{~cm}$ ). A cobertura compõe-se de telhas de fibrocimento (absortância $=0,7$ ), câmara de ar e laje de concreto, esta com espessura igual a $10 \mathrm{~cm}$. As transmitâncias térmicas das paredes e cobertura são respectivamente iguais a 2,43 $\mathrm{W} / \mathrm{m}^{2} . \mathrm{K}$ e $2,06 \mathrm{~W} / \mathrm{m}^{2} . \mathrm{K}$, enquanto as capacidades térmicas valem $152 \mathrm{~kJ} / \mathrm{m}^{2} . \mathrm{K}$ e 233 $\mathrm{kJ} / \mathrm{m}^{2} . \mathrm{K}$.

\subsection{Simulação computacional segundo a NBR 15575-1: procedimento global para classificação do desempenho térmico}

O procedimento de avaliação de desempenho térmico por meio de simulação computacional estabelecido pela NBR 15575-1 (ABNT, 2013) consiste na comparação entre a temperatura máxima do ambiente interno e a temperatura máxima no exterior da edificação, no dia típico de verão. No caso da zona bioclimática 8 , onde está situada a cidade de Maceió, não é necessário verificar o desempenho térmico para condições de inverno. O dia típico de verão é definido em função dos valores de temperatura do ar máximas estabelecidas na própria norma para algumas cidades brasileiras. No caso de Maceió, esta temperatura corresponde a $32,2^{\circ} \mathrm{C}$. Com base no arquivo climático da cidade (RORIZ, 2012), o dia selecionado foi 23/01.

Segundo a norma, o ambiente escolhido para avaliação deve possuir o maior número de paredes expostas. Deve-se selecionar na unidade habitacional um dormitório ou sala de estar que possua janela voltada para oeste e a outra parede exposta voltada para norte. No presente artigo, serão avaliados os quartos e as salas destacadas na Figura 1. Os critérios adotados para a classificação do desempenho térmico dos edifícios em estudo são apresentados na Tabela 1. Convém salientar que a norma define ainda como 
parâmetros para a simulação o emprego de uma taxa de renovação de ar fixa nos ambientes internos, equivalente a 1 renovação/hora, sem a presença de cargas internas (ocupantes, iluminação e eletrodomésticos).

Tabela 1 - Critérios para classificação de desempenho térmico em Maceió

\begin{tabular}{c|c|c}
\hline Nível de desempenho & Critério & Critério - Maceió \\
\hline Mínimo $(\mathrm{M})$ & $\mathrm{T}_{\mathrm{i}, \max } \leq \mathrm{T}_{\mathrm{e}, \max }$ & $\mathrm{T}_{\mathrm{i}, \max } \leq 32,2^{\circ} \mathrm{C}$ \\
\hline Intermediário $(\mathrm{I})$ & $\mathrm{T}_{\mathrm{i}, \max } \leq\left(\mathrm{T}_{\mathrm{e}, \max }-1^{\circ} \mathrm{C}\right)$ & $\mathrm{T}_{\mathrm{i}, \max } \leq 31,2^{\circ} \mathrm{C}$ \\
\hline Superior $(\mathrm{S})$ & $\mathrm{T}_{\mathrm{i}, \max } \leq\left(\mathrm{T}_{\mathrm{e}, \max }-2^{\circ} \mathrm{C}\right)$ & $\mathrm{T}_{\mathrm{i}, \max } \leq 30,2^{\circ} \mathrm{C}$ \\
\hline
\end{tabular}

$\mathrm{T}_{\mathrm{i} \text {, max }}$ : valor máximo da temperatura do ar no interior da edificação

$\mathrm{T}_{\mathrm{e}, \max }$ : valor máximo da temperatura do ar no exterior da edificação

\subsection{Simulação computacional segundo o RTQ-R: procedimento de avaliação da envoltória}

De acordo com o RTQ-R, o parâmetro graus-hora de resfriamento (GHR) é determinado a partir da somatória da diferença da temperatura operativa horária nos ambientes de permanência prolongada, quando esta se encontra superior à temperatura de base, que por sua vez equivale a $26^{\circ} \mathrm{C}$ (PROCELINFO, 2014). O indicador GHR de cada ambiente de permanência prolongada da UH é comparado com valores de referência indicados para cada zona bioclimática. A classificação do nível de eficiência energética da envoltória é, portanto, realizada em função de um parâmetro de desempenho térmico e apresenta limites diferenciados, podendo variar do nível "A" ao nível "E", sendo o nível "A" o indicativo do melhor desempenho (Tabela 2).

Tabela 2 - Critérios para classificação do nível de eficiência energética da envoltória em Maceió

\begin{tabular}{crl}
\hline Eficiência & \multicolumn{2}{c}{$\mathbf{G H}_{\mathbf{R}}$} \\
\hline $\mathbf{A}$ & \multicolumn{2}{c}{$\mathrm{GH}_{\mathrm{R}} \leq 2070$} \\
\hline $\mathbf{B}$ & 2070 & $<\mathrm{GH}_{\mathrm{R}} \leq 4788$ \\
\hline $\mathbf{C}$ & 4788 & $<\mathrm{GH}_{\mathrm{R}} \leq 7639$ \\
\hline $\mathbf{D}$ & 7639 & $<\mathrm{GH}_{\mathrm{R}} \leq 10603$ \\
\hline $\mathbf{E}$ & 10603 & $<\mathrm{GH}_{\mathrm{R}}$ \\
\hline
\end{tabular}

Fonte: Procelinfo (2014)

O procedimento de simulação proposto para edificações naturalmente ventiladas diferencia-se daquele proposto pela NBR 15575-1 por avaliar dados anuais, ao invés de restringir-se ao dia típico de verão. Além disso, considera o efeito da ventilação natural, simulada com base nos dados de direção e velocidade do vento das $8760 \mathrm{~h}$ do arquivo climático, bem como a presença de ocupantes e a existência da iluminação artificial e de outros equipamentos, conformes padrões de uso previamente definidos.

Considerando-se os diferentes parâmetros adotados em cada procedimento de simulação, buscou-se identificar se ambientes bem classificados segundo a NBR 155751 manteriam também uma boa classificação segundo o RTQ-R e vice-versa. Os resultados obtidos para o edifício habitacional em estudo são apresentados no item 4.1. 


\subsection{Simulação da ventilação natural}

O aproveitamento da ventilação natural para o condicionamento passivo de edificações em Maceió, de clima quente e úmido, é de suma importância. Entretanto, softwares destinados à avaliação termoenergética não contemplam o cálculo dos fluxos de ar no exterior e interior da edificação de forma tão detalhada quanto programas CFD (Computed Fluid Dynamics). Estes possibilitam quantificar a velocidade do ar, considerando a interferência de obstáculos presentes no entorno, bem como o efeito de diferentes orientações e da porosidade do edifício, para diferentes incidências de vento. Também possibilitam o cálculo das pressões no exterior do edifício causadas pelo vento, sendo que regiões com maiores diferenças de pressão indicam a possibilidade de maior movimentação de ar, o que favorece a ventilação cruzada caso as aberturas sejam inseridas em tais regiões. O software PHOENICS VR 3.6.1 (CHAM, 2005) é um desses programas, fornecendo resultados gráficos que podem ser apresentados em forma de vetores e/ ou campos de cores.

No presente trabalho, o edifício em análise foi simulado considerando-se a incidência da ventilação Sudeste, frequente em todos os meses do ano. Adotou-se uma velocidade média igual a 2,73 m/s (com base no arquivo climático de Maceió), corrigida de acordo com as condições de entorno suburbano, para o cálculo do gradiente de vento. Os resultados obtidos permitiram avaliar as condições de aproveitamento da ventilação em função do posicionamento das aberturas existentes, complementando os resultados das simulações realizadas com o software EnergyPlus.

\section{RESULTADOS E DISCUSSÃO}

\subsection{Simulação computacional: NBR 15575-1 versus $R T Q-R$}

A Tabela 3 apresenta a síntese dos resultados das simulações realizadas segundo os procedimentos da NBR 15575-1 e do RTQ-R. Os resultados ora apresentados restringem-se aos quartos de menor área e às salas das unidades habitacionais localizadas no pavimento térreo (Pav. 1) e último pavimento (Pav. 4). Os parâmetros de avaliação considerados pela norma e pelo regulamento foram, respectivamente:

a) Diferença entre a temperatura máxima do ar interior e a temperatura máxima externa no dia típico de verão (23/01), resultado na classificação do desempenho térmico segundo os níveis Mínimo, Intermediário ou Superior;

b) Total de Graus Hora de Resfriamento (GHR) obtidos durante o ano em cada ambiente, calculados para uma temperatura base de $26^{\circ} \mathrm{C}$, a partir da temperatura operativa obtida no interior dos ambientes analisados.

Segundo a NBR 15575-1, verifica-se que a maioria dos ambientes localizados no térreo foi classificada com o nível Superior, enquanto na cobertura a classificação predominante foi nível Intermediário. Entretanto, como dois ambientes foram classificados com nível Mínimo, esta seria a classificação final do edifício. Convém salientar que a temperatura de referência para a classificação, $32,2{ }^{\circ} \mathrm{C}$, é bastante elevada, o que favorece o atendimento à exigência da norma para a obtenção do nível Mínimo. A Figura 3 ilustra a variação da temperatura do ar no interior de ambientes que obtiveram classificações nível Superior e Intermediário: a sala 2, no pav. 1 e no pav. 4. Ambos os ambientes apresentam a janela voltada para oeste, sendo mantidos sob uma 
taxa fixa de infiltração (1 renovação/h). O contato com a coberta resultou em uma elevação de $1,6^{\circ} \mathrm{C}$ na temperatura máxima da sala situada no último pavimento.

Tabela 3 - Resultados da avaliação dos ambientes da edificação

\begin{tabular}{|c|c|c|c|c|c|c|}
\hline \multirow[b]{2}{*}{ Pavto. } & \multirow[b]{2}{*}{ Ambientes } & \multirow[b]{2}{*}{ No. UH } & \multicolumn{2}{|c|}{ NBR 15575-1 (ABNT, 2013) } & \multicolumn{2}{|c|}{ RTQ-R (INMETRO, 2013) } \\
\hline & & & $\begin{array}{l}\text { Ti-máx } \\
\left({ }^{\circ} \mathrm{C}\right) 23 / 01\end{array}$ & $\begin{array}{l}\text { Classificação de } \\
\text { Desempenho }\end{array}$ & $\begin{array}{c}\mathrm{GHR}\left({ }^{\circ} \mathrm{C}\right) \\
\text { Anual }\end{array}$ & $\begin{array}{c}\text { Nível de Eficiência } \\
\text { Energética } \\
\text { da envoltória }\end{array}$ \\
\hline \multirow{8}{*}{1} & \multirow{4}{*}{ Salas } & 1 & 30,6 & Intermediário & $9.895,0$ & $\mathrm{D}$ \\
\hline & & 2 & 29,5 & Superior & $9.787,0$ & $\mathrm{D}$ \\
\hline & & 3 & 29,7 & Superior & $10.124,9$ & $\mathrm{D}$ \\
\hline & & 4 & 30,3 & Intermediário & $9.987,7$ & $\mathrm{D}$ \\
\hline & \multirow{4}{*}{ Quartos } & 1 & 29,9 & Superior & $10.644,6$ & $E$ \\
\hline & & 2 & 29,4 & Superior & $10.538,2$ & $\mathrm{D}$ \\
\hline & & 3 & 29,3 & Superior & $10.933,8$ & $\mathrm{E}$ \\
\hline & & 4 & 29,6 & Superior & $10.719,0$ & $\mathrm{E}$ \\
\hline \multirow{8}{*}{4} & \multirow{4}{*}{ Salas } & 1 & 31,5 & Mínimo & $18.579,4$ & $E$ \\
\hline & & 2 & 31,1 & Intermediário & $20.837,8$ & $\mathrm{E}$ \\
\hline & & 3 & 30,9 & Intermediário & $21.334,4$ & $\mathrm{E}$ \\
\hline & & 4 & 31,5 & Mínimo & $20.685,1$ & $\mathrm{E}$ \\
\hline & \multirow{4}{*}{ Quartos } & 1 & 30,9 & Intermediário & $20.659,2$ & $\mathrm{E}$ \\
\hline & & 2 & 31,0 & Intermediário & $22.864,6$ & $\mathrm{E}$ \\
\hline & & 3 & 30,8 & Intermediário & $22.921,2$ & $\mathrm{E}$ \\
\hline & & 4 & 30,8 & Intermediário & $21.169,4$ & $\mathrm{E}$ \\
\hline \multicolumn{3}{|c|}{ CLASSIFICAÇÃO DA EDIFICAÇÃO } & \multicolumn{2}{|c|}{ Nível Mínimo } & \multicolumn{2}{|c|}{ Nível E } \\
\hline
\end{tabular}

Figura 3 - Temperatura do ar - 23/01

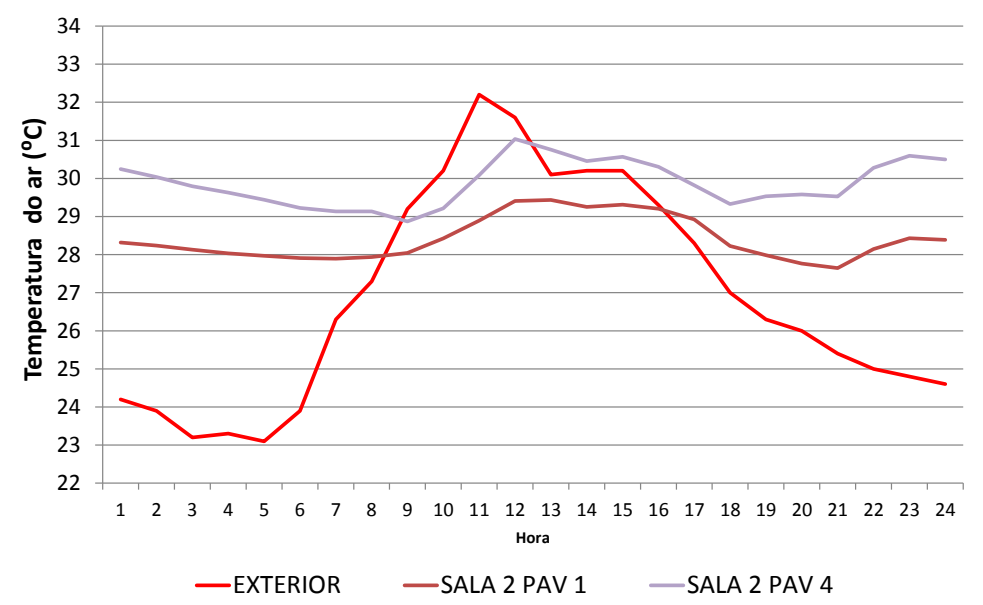

Na avaliação segundo o RTQ-R, verificou-se uma variação no total de GRH nos ambientes em estudo entre $9.787^{\circ} \mathrm{Ch}$ e $22.921,2^{\circ} \mathrm{Ch}$. Para Maceió, o GRH máximo para a obtenção do nível A, melhor nível de eficiência energética, corresponde a $2.070{ }^{\circ} \mathrm{Ch}$ (vide Tabela 2). Portanto, todos os ambientes simulados, principalmente no último pavimento, apresentaram desempenho insatisfatório. A classificação final obtida pelo edifício é Nível "E". Ampliando-se a análise dos resultados, foram quantificados os

\footnotetext{
${ }^{1}$ A classificação final do edifício é resultante da ponderação das classificações de cada unidade habitacional por sua área útil; esta, por sua vez, depende das classificações dos ambientes de permanência
} 
percentuais de horas de desconforto anuais, com base na temperatura operativa igual a $26^{\circ} \mathrm{C}$. Conforme pode-se observar na Figura 4, os percentuais de horas de desconforto atingiram $90 \%$ nos ambientes do Pav. 4. Nas unidades 3 e 4, os quartos com aberturas orientadas a Norte e as salas com aberturas orientadas para Leste ou Oeste alcançaram os piores desempenhos.

Figura 4 - Percentuais anuais de horas de desconforto $\left(\right.$ Temperatura base $=26^{\circ} \mathrm{C}$ )

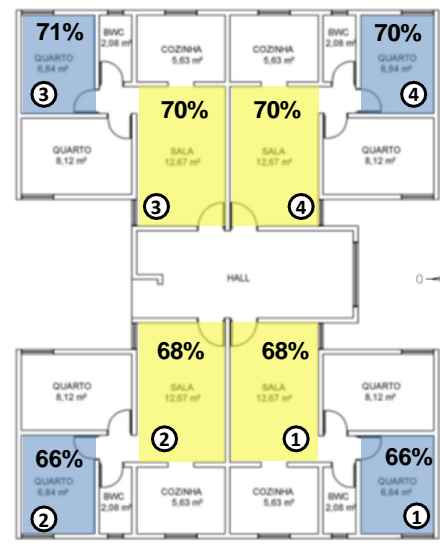

Pavto. 1 - Térreo

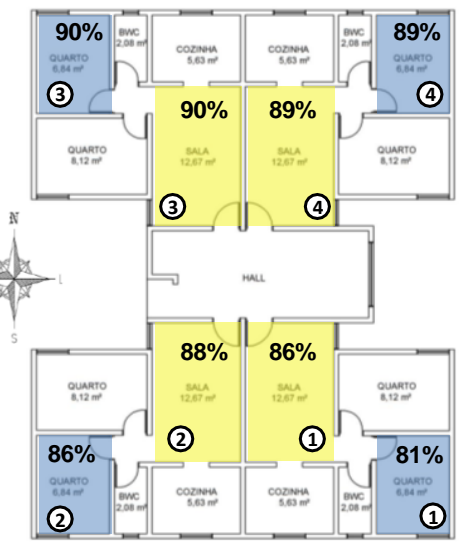

Pavto. 4 - Cobertura

\subsection{Considerações sobre o aproveitamento da ventilação natural}

Tendo em vista a importância desta estratégia para promover o condicionamento passivo em Maceió, o edifício foi avaliado também com o auxílio do software PHOENICS VR 3.6.1, obtendo-se os resultados apresentados a seguir.

A Figura 5 ilustra os coeficientes de pressão obtidos para o edifício, sob incidência do vento SE, adotando-se como referência um plano horizontal interceptando o centro geométrico das aberturas do pav. 1 e pav. 4. Na legenda (planta-baixa, canto inferior direito), os ambientes destacados em amarelo representam as salas e os ambientes destacados em azul, os quartos.

\section{Figura 5 - Simulação da ventilação natural no exterior do edifício (plano de} referência horizontal)

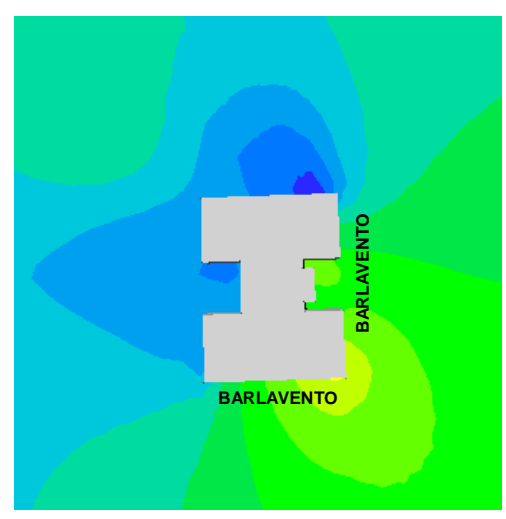

Pavto. 1 - Térreo $(h=1,5 \mathrm{~m})$

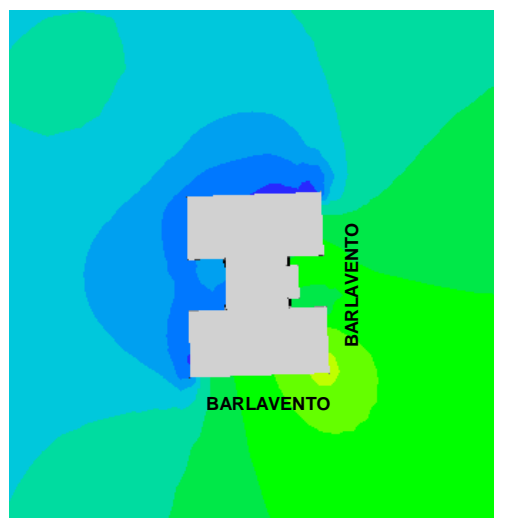

Pavto. $4(\mathrm{~h}=10,5 \mathrm{~m})$
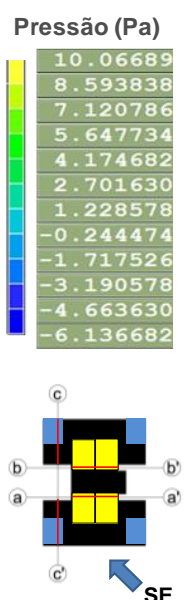

prolongada de cada unidade habitacional e da ponderação das mesmas por suas áreas úteis. Portanto, a classificação final do edifício, considerando-se as 16 unidades habitacionais e os ambientes de permanência prolongada pertencentes a cada uma (quartos e sala), é nível "E". 
Enquanto os ambientes com fachadas à barlavento (junto às fachadas $\mathrm{S}$ e LE, unidades 1 e 2) apresentam uma exposição favorável ao aproveitamento da ventilação, os ambientes situados à sotavento (fachadas $\mathrm{N}$ e O) encontram-se prejudicados.

Quanto à disposição das aberturas, verifica-se que há pouca diferença de pressão entre as aberturas orientadas à $\mathrm{N}$ e $\mathrm{O}$, limitando o aproveitamento da ventilação, principalmente nos quartos da unidade no. 3. Tal condição desfavorável é confirmada quando se observa os resultados da Figura 4, pois estes ambientes apresentaram os maiores percentuais de desconforto. Já na unidade 4, a inserção de aberturas de entrada de ar na fachada LE possibilitaria a ventilação cruzada no quarto em destaque.

A Figura 6 ilustra a visualização do comportamento da ventilação no exterior do edifício de acordo com planos de referência verticais, conforme indicado na legenda (secções aa', bb' e cc'). Verifica-se a formação de uma zona de esteira à sotavento do edifício, assim como uma zona de estagnação na área situada ao centro do mesmo, conforme destacado na seção cc'. Embora no bloco voltado para sul verifique-se diferença de pressão entre as fachadas opostas, a disposição dos ambientes internos não possibilitaria a disposição de aberturas para o aproveitamento da ventilação cruzada neste caso (vide Figuras 4 e 5).

\section{Figura 6 - Coeficientes de pressão no exterior do edifício: seções verticais}

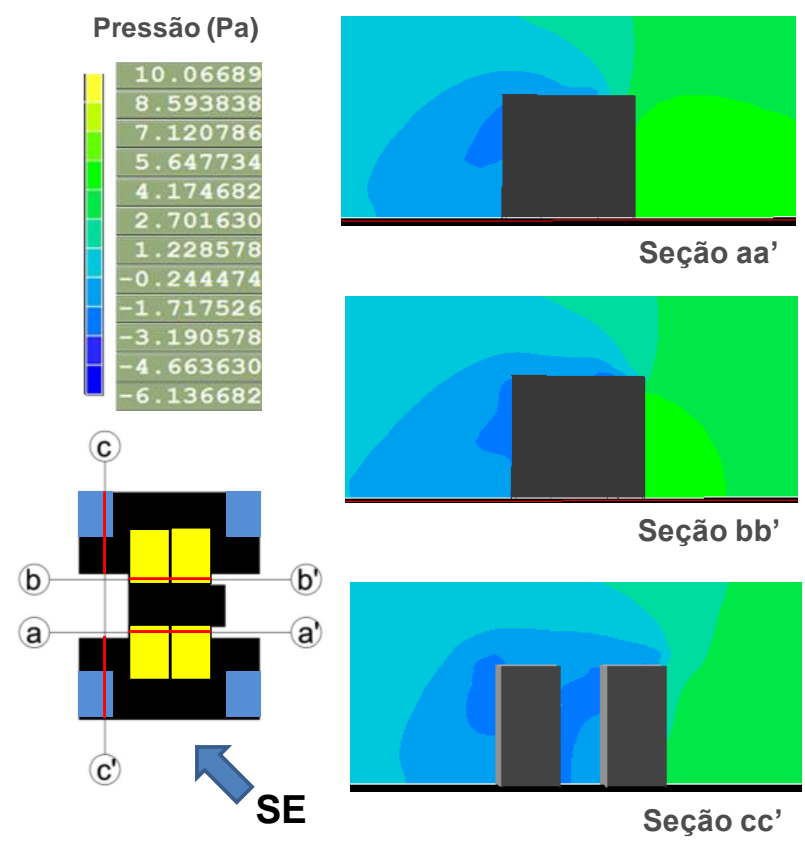

\section{CONSIDERAÇÕES FINAIS}

Os resultados ora apresentados demonstram a distinção nas classificações de desempenho obtidas pelos ambientes em estudo, de acordo com o tipo de abordagem utilizada nas simulações. Enquanto os ambientes analisados foram classificados com níveis "Intermediário" ou "Superior" pela NBR 15575-1, obtiveram níveis "E" de eficiência energética, a mais baixa classificação possível, pelo fato de ultrapassarem os limites do indicador graus-hora de resfriamento estabelecidos pelo RTQ-R. 
Pode-se concluir que o procedimento de simulação computacional adotado pela NBR 15575-1 apresenta limitações importantes enquanto instrumento representativo para a avaliação do desempenho térmico, por ser restrito ao dia típico e empregar uma taxa de ventilação fixa, especialmente nas localidades onde a ventilação natural é a principal estratégia capaz de favorecer o conforto térmico. Já o RTQ-R avalia a influência da variação anual da temperatura no desempenho térmico, porém apresenta limitações quanto ao efeito da ventilação natural no interior dos ambientes. Com o auxílio de ferramentas CFD, torna-se possível obter informações mais precisas quanto às possibilidades de aproveitamento da ventilação natural, contribuindo para a definição de soluções projetuais capazes de favorecer um desempenho térmico adequado às necessidades dos usuários.

\section{AGRADECIMENTOS}

Ao CNPq, pela concessão de bolsa de iniciação científica.

\section{REFERÊNCIAS}

ASSOCIAÇÃO BRASILEIRA DE NORMAS TÉCNICAS. NBR 15575-1: Edifícios habitacionais até cinco pavimentos - desempenho. Rio de Janeiro: ABNT, 2013.

BRASIL. Ministério do Desenvolvimento, Indústria e Comércio Exterior. Instituto Nacional de Metrologia, Normalização e Qualidade Industrial (INMETRO). Portaria $\mathbf{n}^{\mathbf{0}} \mathbf{1 8}$, de 16 de janeiro de 2012. Regulamento Técnico da Qualidade para o Nível de Eficiência Energética de Edificações Residenciais (RTQ-R). Brasília, DF, 2013. Disponível em <http://www.inmetro.gov.br/legislacao/rtac/pdf/RTAC001788.pdf>. Acesso em: 19 mai 2013.

CARTILHA MCMV. Minha casa, minha vida: moradias para as família, renda para os trabalhadores, desenvolvimento para o Brasil. CAIXA/ Governo Federal, 2012, 47p. Disponível em: http://downloads.caixa.gov.br/_arquivos/habita/mcmv/CARTILHACOMPLETA.PDF. Acesso em: 19 mai. 2013.

CBIC. Desempenho de edificações habitacionais: guia orientativo para atendimento à norma ABNT NBR 15575/2013. Câmara Brasileira da Indústria da Construção. Fortaleza: Gadioli Cipolla Comunicação, 2013.

\section{CHAM. PHOENICS VR 3.6.1. 2005. 1 CD-ROM.}

RORIZ, M. Arquivos climáticos em formato EPW. São Carlos, SP, 2012. Disponível em < http://www.labeee.ufsc.br/downloads/arquivos-climaticos/formato-epw>. Acesso em: 15 abr 2014.

PROCELINFO. Manual para aplicação do RTQ-R. Disponível em: < http://www.procelinfo.com.br/main.asp?View $=\{5$ A08CAF0-06D1-4FFE-B335-

95D83F8DFB98 $\} \&$ Team $=\&$ params $=$ itemID $=\{$ FE982F06-7184-4E8E-B74A-

$A 7 A D 099 A B C 13\} ; \& U I P a r t U I D=\{05734935-6950-4 E 3 F-A 182-629352 E 9 E B 18\}>$. Acesso em: 19 mai. 2014.

US-DOE. U.S. Department of Energy. Building Technologies Program. Building Energy Software Tools Directory. Disponível em: $<$ http://apps1.eere.energy.gov/buildings/tools_directory/software.cfm/ID=287/pagename=alpha _list>. Acesso em: 19 mai 2014. 